\title{
A guide to the hypodermic needle as a wire passer
}

\author{
Geoffrey G Hallock MD \\ Division of Plastic Surgery, The Lehigh Valley Hospital, Allentown, Pennsylvania, USA
}

\section{GG Hallock. A guide to the hypodermic needle as a wire passer. Can J Plast Surg 2001;9(2):69-71.}

The use of surgical wires as suture or fixation devices is less common today, primarily because their insertion is relatively cumbersome. The ubiquitous hypodermic needle can be a simple, efficient wire passer that can circumvent these difficulties. A guide is presented that correlates the available common needle gauges with different wire calibres. Thus, when an appropriate wire size is selected, the smallest possible needle gauge can be chosen to minimize tissue injury.

Key Words: Hypodermic needle; Surgical wire passer

\section{Utilisation de l'aiguille hypodermique comme guide}

RÉSUMÉ : L'utilisation des soies chirurgicales comme sutures ou dispositifs de fixation est moins courante, surtout à cause de leur insertion relativement encombrante. L'aiguille hypodermique d'utilisation courante peut représenter un guide simple et efficace qui permet de contourner cette difficulté. On présente ici une corrélation entre les calibres d'aiguille couramment offerts et les différents calibres de catgut. Ainsi, lorsque l'on choisit la taille appropriée, le plus petit calibre d'aiguille possible peut être sélectionné afin de réduire l'atteinte tissulaire.

$\mathrm{W}$ ire materials have long had a role in surgery for soft tissue repair or osseous fixation (1-5). Today, many of these applications have been supplanted by modern suture materials, anchor devices or rigid fixation plates $(5,6)$. However, the occasional use of a surgical wire still requires some mechanism for insertion. This has been accomplished by using swaged-on needles, free needles, specialized wire passing needles or instruments, or drill bits or K-wires with eyelets (1). In an office setting or emergency situation, even in the operating theatre, these specialized devices may be unavailable. One solution is to use the ubiquitous hypodermic needle as the wire passer.

\section{MATERIALS AND METHODS}

More often than not, prepackaged wire suture materials can not be readily found, but sterile spools of surgical grade steel wires are a basic component of any facial fracture tray found in most operating rooms. If special needles or instruments for passing these wires through delicate soft tissues or thin fracture fragments are also unavailable, the necessary hole can be created by using a common, hollow hypodermic needle. The lumen of the needle simultaneously is a rigid channel that allows effortless wire passage.

Preferably, any hole made by the hypodermic needle in the role of wire passer should also be as small as possible to cause the least amount of tissue injury. To guide this choice, a correlation between wire calibre and needle gauge was determined by threading a piece of wire from each available spool through progressively smaller gauged needles until the minimum was established (Figure 1).

\section{RESULTS}

An assortment of readily available hypodermic needles ranging from 18 to 23 gauge permits the efficient passage of all commonly stocked surgical wires (Figure 1). The higher the needle gauge, the smaller the lumen diameter and corre-

Correspondence: Dr Geoffrey G Hallock, 1230 South Cedar Crest Boulevard, Suite 306, Allentown, Pennsylvania 18103, USA.

Telephone 610-435-7555, fax 610-770-6390 


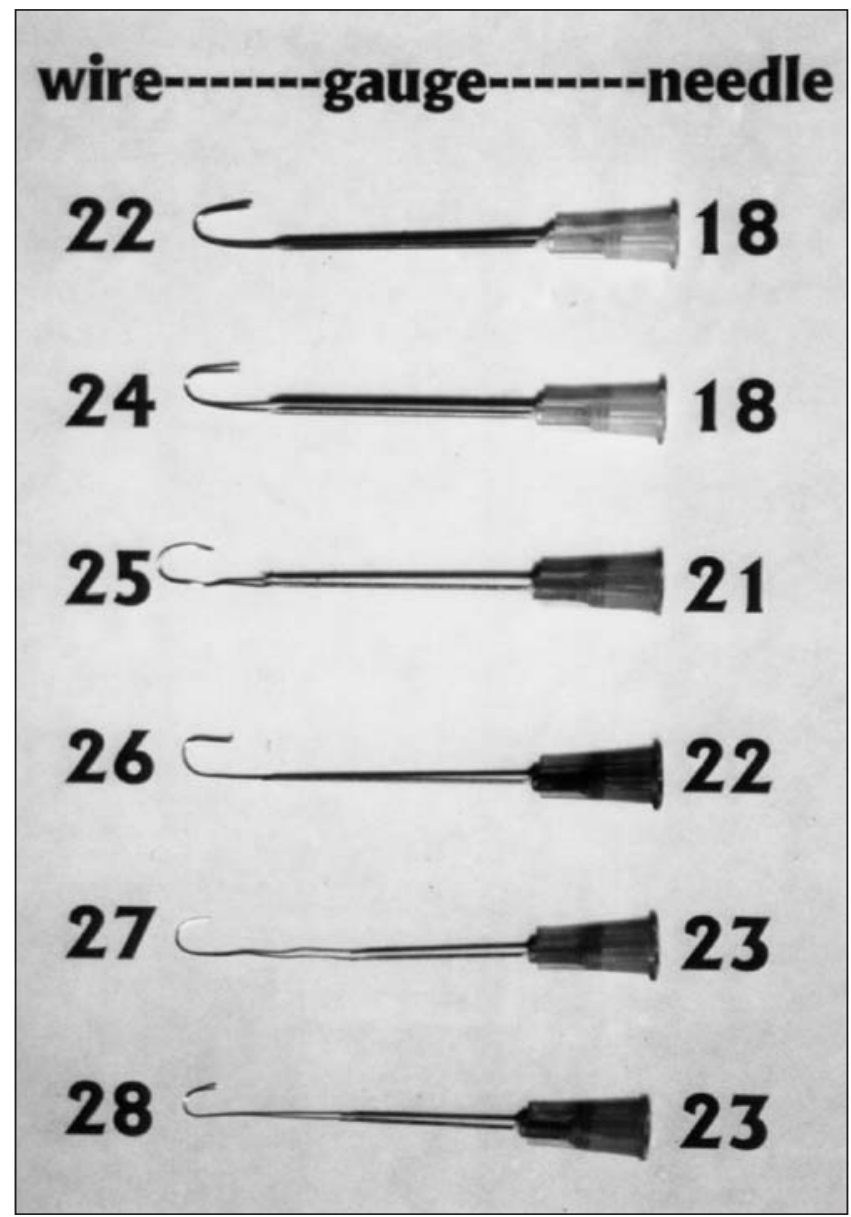

Figure 1) Free surgical wires of stated calibre (left column) have been inserted through the lumen of the smallest possible gauge hypodermic needle (right column) that allows passage

sponding calibre of wire that can be used. The wire selected must be strong enough for the given task, and the needle should be delicate enough not to cause excessive tissue disruption (Figure 2). Various gauge hypodermic needles can also be used as a medically safe and cheap alternative for body piercing, where jewellery of the appropriate size is substituted for threading wire (Figure 3).

\section{DISCUSSION}

Although fine surgical steel wires already swaged onto needles, to simplify their insertion, are commercially obtainable (2), these may not always be available. To use some form of free wire strands requires another method for delivery. Most free surgical needles or wire passing tools require that the wire be doubled back onto itself when threaded, so that this manoeuvre or the instruments may be too large or cumbersome to manipulate through the required tissues. Instead, the smallest possible hypodermic needle first thrust through that tissue, followed by threading the wire through its lumen can be a more efficient and safer method (Figure 2). The hypodermic needle also is a cheap alternative for body piercing that can be repositioned at any site as desired (Figure 3) without risks such as embedment, which is potentially caused by

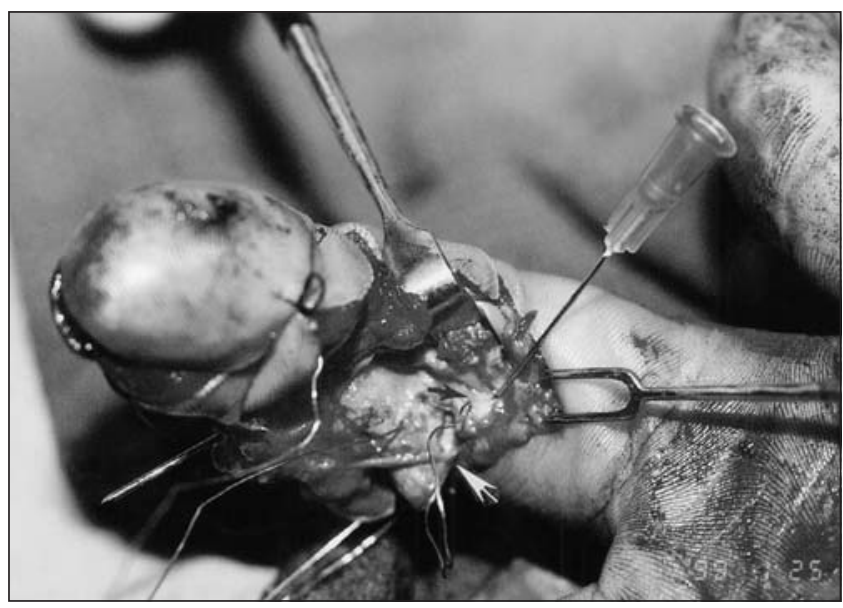

Figure 2) Example of wire passage after volar plate avulsion in an open fracture-dislocation of the index finger proximal interphalangeal joint. The volar plate (black arrow) was advanced and reattached to the base of the middle phalanx by using a 27 gauge transosseous wire. A 23 gauge hypodermic needle thrust through the relatively hard volar plate allowed passage of this wire (white arrow) without causing further tearing

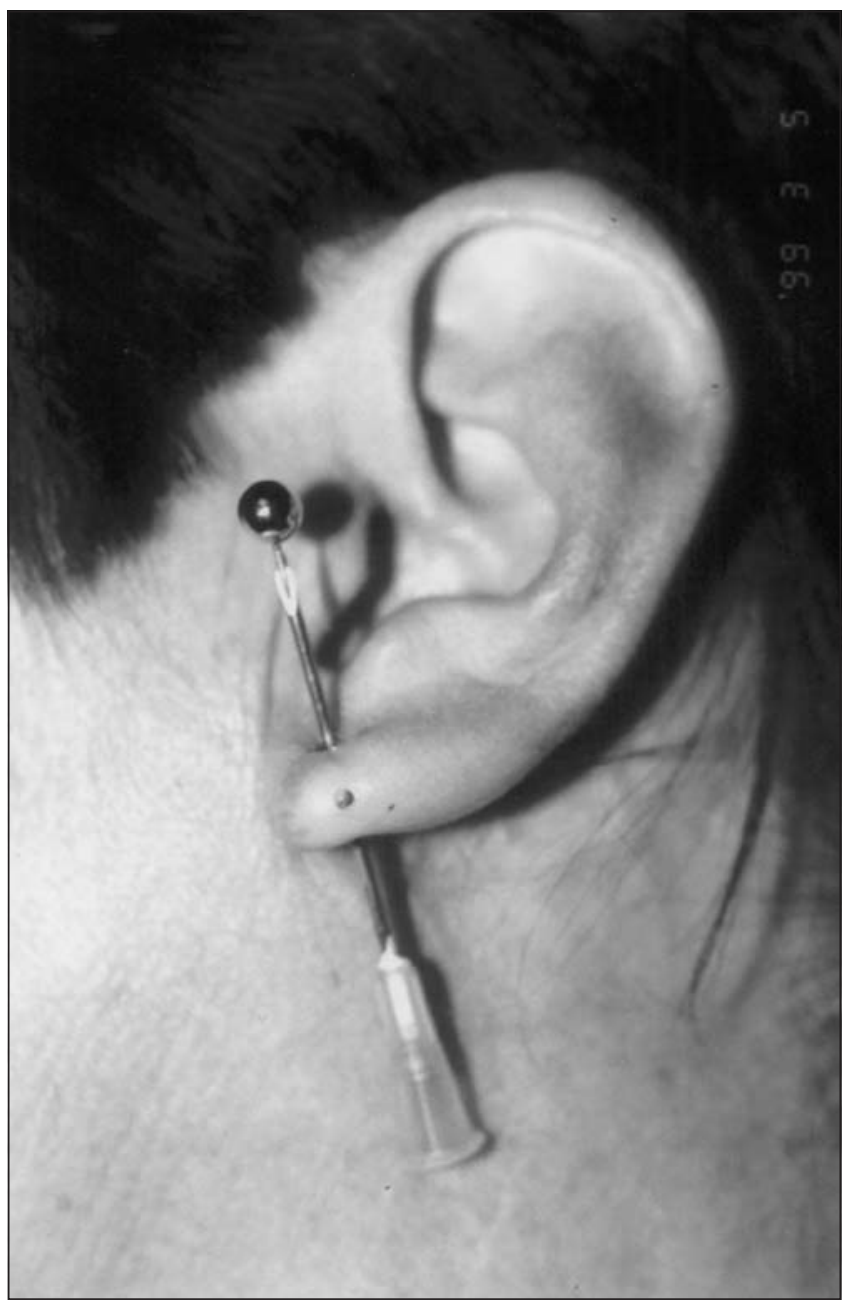

Figure 3) In ear piercing, an 18 gauge hypodermic needle accepts most earring posts. The needle creates a hole at the presumed best aesthetic site and allows the post to be placed into the lumen to pass easily through the earlobe before the backing is attached 
commercial spring-loaded 'guns' (7). The calibre of wire or jewelry post that can be passed efficiently in this manner can be correlated with the best needle gauge by using the guide as illustrated in Figure 1.

\section{REFERENCES}

1. Dingman RO, Natvig P. The Men of the Elder Days, Surgery of Facial Fractures. Philadelphia: WB Saunders, 1964:133-209.

2. Barmakian JT, Lin H, Green SM, Posner MA, Casar RS. Comparison of a suture technique with the modified Kessler method: Resistance to gap formation. J Hand Surg [Am] 1994;19:777-81.
3. Weeks PM. Proximal Interphalangeal Joint, Acute Bone and Joint Injuries of the Hand and Wrist. St Louis: CV Mosby, 1981:161-98.

4. Dray GJ, Eaton RG. Dislocations and ligament injuries in the digits. In: Green DP, ed. Operative Hand Surgery, 2nd edn. New York: Churchill Livingstone, 1988:782-3.

5. Rohrich RJ, Watumull D. Comparison of rigid plate versus wire fixation in the management of zygoma fractures: a long-term follow-up clinical study. Plast Reconstr Surg 1995;96:570-5.

6. Hallock GG. The Mitek mini GII anchor introduced for tendon reinsertion in the hand. Ann Plast Surg 1994;33:211-3.

7. Muntz HR, Cui DJ, Asher BF. Embedded earrings: a complication of the ear-piercing gun. Int J Pediatr Otorhinolaryngol 1990;19:73-6. 